\title{
An overview: origins and development of green chemistry
}

\author{
J. A. Linthorst
}

Published online: 1 October 2009

(C) The Author(s) 2009. This article is published with open access at Springerlink.com

\begin{abstract}
This article provides an overview of the origins and development of green chemistry. Aiming to contribute to the understanding of green chemistry, basically from a historical point of view, this overview argues that contextual influences and the user friendliness of the term are drivers for the explosive growth of green chemistry. It is observed that political support for its development has been significant, in which the Pollution Prevention Act of 1990 was a formal political starting-point, but informally the origins of green chemistry go back to before 1990. US EPA played an important role in all this, but did not solely contribute to the growth of green chemistry.
\end{abstract}

Keywords Green chemistry · History of chemistry · Pollution Prevention Act of 1990 . US EPA

\section{Introduction}

In the 1980s and 1990s, several environmentally conscious terms entered the chemical arena, e.g. clean chemistry, environmental chemistry, green chemistry, benign chemistry and sustainable chemistry. These terms are not well-defined and subject to debate among chemists (Eissen and Metzger 2002; Centi and Perathoner 2003). I would like to contribute to a better understanding of these terms by studying one of these terms: green chemistry. As Fig. 1 clearly shows, this term has become, and still is, the most popular among a number of alternatives. ${ }^{1}$

${ }^{1}$ The results are based on searching of the particular terms in the scientific search engine ISI Web of Knowledge: Web of Science. In addition, the scientific search engines Scopus and PiCarta outline similar data, which enforces the reliability of the trend displayed in Fig. 1.

\section{J. A. Linthorst ( $\square)$}

Department of History, Maastricht University, P.O. Box 616, 6200 MD Maastricht, The Netherlands e-mail: linthorstwerk@ hotmail.com

\section{J. A. Linthorst}

Descartes Centre for the History and Philosophy of the Sciences and the Humanities,

Utrecht University, Janskerkhof 3a, 3512 BK Utrecht, The Netherlands 


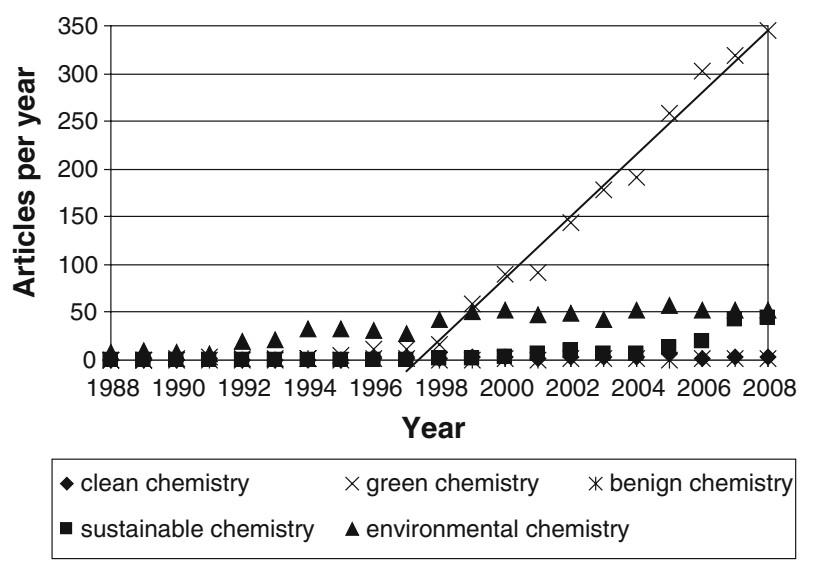

Fig. 1 The use of environmentally conscious terms in titles, abstracts and keywords of articles over the 1988-2008 period. Source: ISI Web of Knowledge: Web of Science

Since 1998 the use of this term has clearly been growing rapidly in a linear fashion. Not based on a particular chemical philosophy, Cathcart (1990) was probably the first chemist who used the term in the title of an article. Cathcart discussed the advantages and disadvantages of the significant growth of the Irish chemical industry. In 1996, this situation changed with the publishing of Green Chemistry: An Overview in Green Chemistry: Designing Chemistry for the Environment (Anastas and Williamson 1996a, b). In contrast with Cathcart and other chemists in the 1990-1996 period, ${ }^{2}$ this publication presented a green chemistry philosophy that was significantly cited, which will be explained in the next sections. Advocates of this green chemistry philosophy commented that it "has been driven by new knowledge" (Anastas et al. 1999). They commented that "knowledge" is a driver for the growth of green chemistry. Of course, chemists have disseminated many viewpoints on the development of green chemistry. For instance, Leitner (1999) argued that clean chemistry, green chemistry and sustainable chemistry are essentially the same. Quite recently, a comparable opinion was put forward during the 1st meeting of the Working Party on Green and Sustainable Chemistry (European Association for Chemical and Molecular Sciences) on 28th February 2008 about the prefixes sustainable and green (Tundo 2008). As far as prefixes are concerned, members of the Working Party on Green and Sustainable Chemistry commented that there was "no consensus in the scientific community". Moreover, Winterton (2001) mentioned he is not certain that all "chemistry that calls itself green is necessarily going to lead to pollution prevention".

Considering the explosive growth of green chemistry and the ensuing discussion among chemists, I think the time has come to study green chemistry from a historical point of view. In short, I will attempt to sketch the historical development of green chemistry and some dominant factors in its growth, especially around 1998. Following Rip (1977), a philosopher and sociologist of science, this article also discusses the internal development of green chemistry. Apart from institutional and interactional history, Rip emphasized the importance of studying the internal development of research areas in the history of science. The internal development, or say paradigm development, will be used in my analysis of

2 See for example Amato (1993) and Collins (1995). They used the term green chemistry without a welldefined green chemistry philosophy. 
green chemistry as a scientific specialty. In this respect, Mullins (1972) and Crane (1969a) proposed some characteristics of scientific specialties. Related to institutional developments (like journals and other communication networks), a scientific specialty is characterized by the sharing of a paradigm by scientists who are in the same scientific specialty and the establishment of norms "to govern the kind of research to be done and the manner in which it was to be done and presented" (Mullins 1972). In the same spirit as Crane (1969b), I will use citation statistics in my discussion of the mutual relationship between the historical development and the internal development. In summary, I will discuss the role of green chemistry knowledge in relation to the growth of green chemistry (see Fig. 1).

For a better understanding of the historical development, I have divided my article into three periods (cf. Fig. 1). The first period has no formal starting-point, but roughly ends in 1993, because from then on a marginal increase in the use of the term green chemistry is observed in Fig. 1. This marginal increase roughly ends in 1998. Obviously, this year is a sort of transition, because from then on a huge linear growth has taken place. Therefore, the third period covers the years 1999-2008.

\section{The first period: the origins of green chemistry within US EPA}

Rachel Carson (1962) set the agenda for protection of the environment with her Silent Spring. From then on, gradually, politics got involved, resulting in the foundation of the US Environmental Protection Agency (US EPA) in 1970 by President Nixon. Traditionally, US EPA adopted a command and control policy in the execution of environmental regulations. In the mid 1980s, a shift in paradigm occurred in the OECD (Organisation for Economic Co-operation and Development) countries. During the 1985 meeting of the Environment Ministers of the OECD countries, the focus was on three themes: Economic Development and the Environment, Pollution Prevention and Control and Environmental Information and National Reviews. Between this meeting and 1990 several (OECD Council Acts) Decisions, Decisions-Recommendations and Recommendations were formulated. ${ }^{3}$ In view of this article, some important ones were "Co-operative Investigations and Risk Reduction of Existing Chemicals" and "Integrated Pollution Prevention and Control" (Long 2000). Internationally, the idea of command and control policy (often referred to as end-of-pipeline control) shifted towards an approach of pollution prevention.

A shift in paradigm of the US EPA policy also started in the 1980s. Pollution prevention instead of end-of-pipeline control had to become the option of first choice, as was confirmed by the US EPA officers David Stephan and John Atcheson in their The EPA's approach to pollution prevention (Stephan and Atcheson 1989). This new approach was not intended to soften environmental regulations and goals. If necessary, US EPA was still mandated to impose fines in enforcing environmental regulations. US EPA and the chemical industry, cooperating in developing new processes more and more, mainly based this paradigm shift on a shared financial interest and modification of old processes based on the pollution prevention principle (Stephan and Atcheson 1989). As a consequence, in 1988 the Office of Pollution Prevention and Toxics was established within the US EPA, even before the concept was politically formalized in 1990 and therefore illustrating the urge for pollution prevention (Stephan and Atcheson 1989). In 1990, US Congress passed

\footnotetext{
3 The former Director for Environment of the OECD, Bill L. Long, wrote a comprehensive history on international environmental issues and the OECD (Long 2000).
} 
the "Pollution Prevention Act of 1990" under the Administration of President George H.W. Bush (Pollution Prevention Act 1990). This occurred in a bad economic period that also featured serious environmental problems. ${ }^{4}$ Consequently, the US Congress concluded that the United States of America produced "millions of tons of pollution". Controlling this pollution entailed a great deal of expense, approximately "tens of billions of dollars per year" (Pollution Prevention Act 1990, p. 617). This emphasized the environmental and economic urge to adopt the policy of pollution prevention.

The findings of the US Congress outline that there was a shared interest of government (e.g. US EPA) and chemical industry to cooperate and meet environmental and economic goals, which is described in the section "EPA Activities" (Pollution Prevention Act 1990). The proposed activities included the establishment of "an annual award program to recognize a company or companies which operate outstanding or innovative source reduction programs" and to "facilitate the adoption of source reduction techniques by businesses" (Pollution Prevention Act 1990, p. 619). Following the Pollution Prevention Act (1990, p. 623) extra money was reserved for US EPA to develop new programs aiming at pollution prevention. One of these was "Alternative Synthetic Design for Pollution Prevention" developed within the Office of Pollution Prevention and Toxics (Anastas and Farris 1994a). On 22-27 August 1993, the first symposium based on this program, "Benign by Design: Alternative Synthetic Design for Pollution Prevention", was held in Chicago and sponsored by the Division of Environmental Chemistry Inc. (American Chemical Society). The organizers of this symposium collected the results of this symposium, together with some other contributions on the same topic, in Benign by design: alternative synthetic design for pollution prevention (Anastas and Farris 1994b).

\section{The second period: $1993-1998$}

Operating in the spirit of the Pollution Prevention Act, US EPA was mainly focused on networking, ${ }^{5}$ as is illustrated by the first book resulting from this symposium. All the authors represent institutes from the USA. At least $50 \%$ of the chapters were officially subjected to input from the chemical industry financially supporting universities or representing their own research results (DuPont and Monsanto Company). In agreement with the Pollution Prevention Act of 1990, a significant number of 8 of the 25 members of the 1994 Advisory Board of the ACS Symposium Series were representatives of the chemical industry. As was to be expected, the input of US EPA was dominant, which is reflected in nine chapters by US EPA financially supporting the academic area, writing chapters in collaboration with authors representing the chemical industry and by writing chapters themselves. Three chapters were written by US EPA representatives. Of course, organizing a symposium is an important aspect of networking, even more so is officially collaborating with other overall organizations, which occurred in January 1993 with NSF (National Science Foundation) and CCR (Council for Chemical Research) (Anastas 1994, p. 18). CCR itself counts members from industry, academia and government. The strong focus on cooperation (or say networking) by US EPA with NSF also resulted in five chapters supported by NSF and one chapter written by representatives of NSF, Kenneth G. Hancock and Margaret A. Cavanaugh. Cavanaugh was also a member of the 1994 Advisory Board

\footnotetext{
${ }^{4}$ For further reading in general on the history of the United States of America, see Norton et al. (1991).

5 For further reading in general on the importance of networking within science see Science in action (Latour 1987) and Science in context (Barnes and Edge 1982).
} 
(ACS Symposium Series). An important role was played by Hancock, who was Director of the Division of Chemistry, Mathematics and Physical Sciences Directorate of the NSF (Anastas and Farris 1994c). Hancock focused on environmental processing: within the Division of Chemistry (NSF) together with CCR, he developed the funding program "Environmentally Benign Chemical Synthesis and Processing Program" (Anastas 1994, p. 18). Therefore, US EPA took part in an already existing network, comprising members of industry, academia and government. Based on the Pollution Prevention Act of 1990, this must have been relatively easy, because US EPA was granted extra money by the US Congress. The connections between US EPA and chemical industry are also reflected by the appointment of former US EPA Administrators to the posts of environmental director within companies (Hoffman 1997, p. 125), e.g. Reilly (DuPont), Ruckelshaus (Monsanto) and Train (Union Carbide).

A second symposium was organized by Joseph J. Breen (US EPA) and Allan Ford (Division of Environmental Chemistry Inc.) on 21-25 August 1994 (Washington, DC), again sponsored by the Division of Environmental Chemistry Inc. (American Chemical Society). This symposium included presentations "that focused on environmentally benign chemistry research in the international arena" (Anastas and Williamson 1996b, p. xi). Apparently, internationalization added a new dimension to networking activities. Consequently, this book included chapters written by authors representing institutes and companies from Japan (Chap. 2) and especially Italy which contributed five of the 17 chapters (Chaps. 3, 5, 6, 7 and 8). Chapter 7 was written by Pietro Tundo, who organized the Summer Schools on Green Chemistry in Venice in later years (Tundo 2001).

The main purpose of the Pollution Prevention Act was of course pollution prevention in order to meet environmental and economic goals. Therefore, US EPA proposed a chemical philosophy to accomplish these goals. They referred to this philosophy with "benign by design chemistry" and sometimes "benign chemistry". 6 This terminology changed around the second symposium, in which the term green chemistry was constantly used. This shift must have been deliberate (Roberts 2005), as developing a chemical process which is truly environmentally benign is very difficult, if not impossible. Advocates of this chemistry realized this, because they argued "One obvious but important point: nothing is benign" (Anastas and Williamson 1996a, p. 2). The first chapters of these books both contain an overview of this chemical philosophy. In the two chapters the chemical philosophy was essentially the same (as will be explained hereafter), but the terminology was not. Considering ISI Web of Knowledge: Web of Science, Chap. 1 of his first book was cited 2 times and Chap. 1 of his second book 21 times, which is significantly more. This indicates that the 'language' of this chemistry, independent of the associated philosophy, also contributed to the growth of green chemistry.

As promised, in the following I will first shortly explain the trunk lines of the proposed philosophy within US EPA. Then I will show that this philosophy did not alter simultaneously with the shift in terminology.

First, what is this philosophy? The chemical philosophy proposed is not a theory or law like the Nernst equation, reaction mechanisms or the Schrödinger equation. In fact, it is a combination of several chemical concepts, a conceptual framework that can be used in the design of chemical processes achieving environmental and economic goals by way of preventing pollution. This comprises for instance ambient reaction conditions, renewable feedstocks and minimization of reaction steps. Two concepts form the heart of this green chemistry philosophy. The first concept is Atom Economy, which is "at the foundation of

${ }^{6}$ See for Example Anastas (1994) and Breen and Anastas (1994). 
Scheme 1 a illustrates a $[2 \sigma+2 \sigma+2 \pi]$ cycloaddition and b an aromatic substitution reaction $\mathbf{a}$
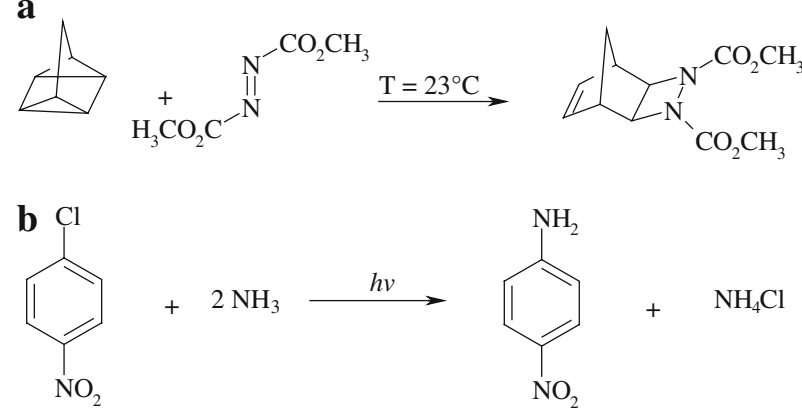

the principles of green chemistry", and, the other one is catalysis, which is a "fundamental area of investigation" (Anastas and Williamson 1996a, pp. 13-14).

Advocates of this green chemistry actively put these two concepts forward, especially the concept of catalysis. ${ }^{7}$ Active use of these concepts by chemists might contribute to achieving environmental and economic prosperity. Of course, the catalysis concept was not new at that time and already existed before the 1990s, which is why it is not explained here. Nor are the environmental advantages of catalyzed processes. The concept of Atom Economy is a different matter: in 1991, B.M. Trost introduced this concept in Science (Trost 1991). Based on arbitrarily chosen reaction equations, this concept is explained in Scheme 1.

Following the "on water protocol", reaction equation 1a outlines the synthesis of a 1,2-diazetidine (Klijn and Engberts 2005). In this reaction, all the atoms of the reactants are transformed into one reaction product. This is defined as 100\% Atom Economy, which means that there are no by-products (waste). This contrasts with the substitution reaction of Scheme 1b, which outlines the synthesis of para-nitroaniline. Next to the desired product (para-nitroaniline), this synthesis generates a by-product (ammoniumchloride) that "is highly unfavorable" (Stern 1994). Considering this by-product, equation 1b correlates with Atom Economy of less than $100 \%$. In terms of pollution prevention, it is obvious that $100 \%$ Atom Economy fits the green chemistry philosophy developed within US EPA.

Secondly, I have argued that this philosophy did not alter simultaneously with the change in terminology. To prove this, I have to make a short jump in time. Advocates of this green chemistry published a lot of articles and books on green chemistry. In most cases, they also explained the philosophy of green chemistry, of which they gave several definitions. In 1998, they defined green chemistry as "a particular type of pollution prevention" by referring to the first overview of this philosophy, the chapter that was named "Benign by Design Chemistry" (Anastas and Warner 1998, p. 8). This clearly shows that the philosophy did not alter with the accompanied shift in terminology.

Based on the Pollution Prevention Act, political support of the concept of green chemistry continued in the following years. In 1995 the Presidential Green Chemistry Challenge Awards were launched under the Administration of President Clinton and administrated by US EPA (Anastas et al. 1999). The first awards were presented in 1996 at the National Academy of Sciences to the following companies: Monsanto, Dow Chemical, Rohm \& Haas and Donlar Corporation (now NanoChem Solutions, Inc.). In addition, Prof.

\footnotetext{
7 Anastas used the title "Catalysis as a foundational pillar of Green Chemistry" for his article published in the journal Applied Catalysis A: General (Anastas et al. 2001). This emphasizes the importance of the concept of catalysis within this philosophy.
} 
Mark Holtzapple (Texas A \& M University) was granted the Academic Award. ${ }^{8}$ Apparently, political support in this program focused again on cooperating (networking).

In 1997 a new dimension was added to the development of green chemistry: the launching of the Green Chemistry Institute (GCI), a non-profit organization aimed at the incorporation and dissemination of green chemistry principles. This institute "was founded by several participant organizations", e.g. US EPA, University of North Carolina and "industrial organizations including Hughes Environmental (now Raytheon Environmental) and Praxair" (Anastas et al. 1999). It is obvious that EPA was again part of a network that formally coalesced with the proposed green chemistry philosophy. Considering Fig. 1, 1997 is still the period of marginal growth of green chemistry in terms of publications. From 1990-1998, most of the articles published on green chemistry originated from US EPA. ${ }^{9}$ The output of GCI in this period was marginal, but this changed in later years.

Next to US EPA, another institute came into play. The University of York published a couple of articles, the dominant actor being Prof. James Clark. In advance of the linear growth (Fig. 1) of green chemistry, he published an article on the catalysis of the Knoevenagel reaction in Reactive \& Functional Polymers (Macquarrie et al. 1997). In this article he used the term green chemistry one time (in the keywords), but he did not explain this term. In fact, he didn't propose, or referred to, a particular green chemistry philosophy. But his work was intensively cited, which was not the case for the US EPA works of that time. Clark continued to use the term in the same way. In 1998 he wrote an article in Chemical Communications (Clark and Macquarrie 1998), which was cited approximately 210 times! Considering ISI Web of Knowledge: Web of Science, until 1998 Clark never referred to the green chemistry philosophy developed within US EPA. Clark also focused on networking, because at that time there was "no UK organisation for actively promoting green chemistry as means of sustainable development or to act as a focal point for developing and sharing best practice in green chemistry" (Clark 1998). This resulted in the founding of the Green Chemistry Network (GCN) within the Royal Society of Chemistry (RSC). The proposed activities of GCN were located within the University of York and Clark became the first director of this network. Alongside the establishment of GCN, RSC announced the launching of the new journal Green Chemistry with Clark as its first editor. The first issue of this journal appeared in 1999, as we will see in the next section. Considering the number of citations and Clark's role within GCN and the journal Green Chemistry, it is obvious that Clark became a dominant actor.

In 1998, Anastas, a US EPA representative, and Warner published the 12 principles of green chemistry (Table 1) in the first handbook on green chemistry (Anastas and Warner 1998). The term principles should not be taken too literally here, because it is allowed to look upon them as "guidelines" (Anastas and Kirchhoff 2002), which are fundamentally different from principles. These principles ought to be reflections of the conceptual framework developed in the early 1990s (Anastas and Warner 1998, p. 30). Discourse analysis of this handbook and the former publications (Anastas and Farris 1994b; Anastas and Williamson 1996b) elucidates that the practical work mainly focused on the replacement of hazardous substances, like CFC's, VOC's and heavy metals, and to prevent waste production at the source. This is in accordance with the Pollution Prevention Act and the US Clean Air Act. In general, the practical work was mainly based on several types of catalysis and to a much lesser extent on subfields like supercritical fluids (e.g. Tanko et al.

\footnotetext{
8 All the winners of the Presidential Green Chemistry Challenge Awards are listed on the site of US EPA. See therefore http://www.epa.gov/greenchemistry/pubs/pgcc/past.html (accessed 28 September 2009).

9 Source: ISI Web of Knowledge: Web of Science.
} 
Table 1 The 12 principles of green chemistry. From: P.T. Anastas and J.C. Warner, green chemistry: theory and practice

1. It is better to prevent waste than to treat or clean up waste after it is formed

2. Synthetic methods should be designed to maximize the incorporation of all materials used in the process into the final product

3. Wherever practicable, synthetic methodologies should be designed to use and generate substances that possess little or no toxicity to human health and the environment

4. Chemical products should be designed to preserve efficacy of function while reducing toxicity

5. The use of auxiliary substances (e.g. solvents, separation agents, etc.) should be made unnecessary wherever possible and innocuous when used

6. Energy requirements should be recognized for their environmental and economic impacts and should be minimized. Synthetic methods should be conducted at ambient temperature and pressure

7. A raw material of feedstock should be renewable rather than depleting wherever technically and economically practicable

8. Unnecessary derivatization (blocking group, protection/deprotection, temporary modification of physical/chemical processes) should be avoided whenever possible

9. Catalytic reagents (as selective as possible) are superior to stoichiometric reagents

10. Chemical products should be designed so that at the end of their function they do not persist in the environment and break down into innocuous degradation products

11. Analytical methodologies need to be further developed to allow for real-time, in process monitoring and control prior to the formation of hazardous substances

12. Substances and the form of a substance used in a chemical process should be chosen so as to minimize the potential for chemical accidents, including releases, explosions, and fires

1994; Morgenstern et al. 1996; Anastas and Warner 1998, pp. 104-106), metal oxide surfaces (Simmons 1996) and ionic liquids (Anastas and Warner 1998, p. 25).

In summary, on the eve of the linear growth of green chemistry, we have a handbook that claims to be focused on knowledge and we have the announcement of Green Chemistry. The handbook results from a politically supported network that originates from the US. The announced journal originates to a certain extent from a chemistry network (GCN) within the RSC. Considering Fig. 1, we are now at the start of the linear growth in output. What are the dominant factors of this growth?

\section{The third period: 1999-2008}

Several factors contributed to the growth of green chemistry, as displayed in Fig. 1, the appearance of Green Chemistry being an important one. Figure 2 displays the percentage output contribution of Green Chemistry for articles that contained the term in titles, abstracts and keywords. Since 1999, the contribution of Green Chemistry in terms of output has been significant. In the 2001-2005 period, the number of journals increased enormously, but the percentage contribution of Green Chemistry remained approximately the same.

What is the driver for this growth within the journal Green Chemistry? Moreover, why did RSC choose the title "green chemistry"? In "The second period: 1993-1998", it was shown that RSC planned to launch a new journal in collaboration with GCN and the University of York. Thus next to the networking activities of US EPA a new network was developed. To a certain extent, these networks were familiar with each other, because the 
editor of Green Chemistry referred to the green chemistry developed within US EPA (Clark 1999a). Considering the choice of the title of the journal, Clark argued that the term green chemistry carried a good "combination of widespread use and appreciation, as well as simplicity and impact" (Clark 1999a). Terms like "widespread use", "simplicity" and "impact" outline that the type of term, or say language, was important in choosing the title of the new journal, but what about the role of knowledge. In the first Editorial the editor referred to the handbook of green chemistry developed within US EPA. The (first) scientific editor of Green Chemistry also wrote the first article on green chemistry in this journal (Clark 1999b), which was based on his Inaugural Lecture at the University of York in 1998. However, the editor did not refer to the previously proposed green chemistry works of US EPA at all. This citing behavior is characteristic of the works of the other authors that contributed to the first issue of Green Chemistry by presenting their own research results. In general, the using of the term green chemistry, without properly referring to the green chemistry philosophy developed within US EPA, occurred in many articles shared over approximately 400 journals (including journals like Angewandte Chemie International Edition and Chemistry-A European Journal) (see footnote 9). This is observed for the 1990-2008 period and even within special issues on the topic of green chemistry. In this respect, Chimia devoted a special issue (Year 2000, vol. 54 (9), pp. 492530) to green chemistry shortly after the explosive growth of green chemistry around 1998, which partly explains the decrease in percentage contribution of Green Chemistry in Fig. 2 for 2000. The quest-editor of this journal coalesced with the definition of green chemistry developed within US EPA. How about the authors that contributed to this special issue? None of them refers to the green chemistry works of US EPA. One author, Roderick Chuck, indirectly refers to the 12 principles, but the others do not (Chuck 2000, p. 508).

The networking activities of US EPA continued by delegating a member to the Working Party on Synthetic Pathways and Processes in Green Chemistry, which "was established in 1996, under the auspices of the Commission on Physical Organic Chemistry (Commission III. 2) of the IUPAC Organic and Biomolecular Division" (Bull 2000). This working party initiated a "symposium-in-print on green chemistry" and so it could "promote and

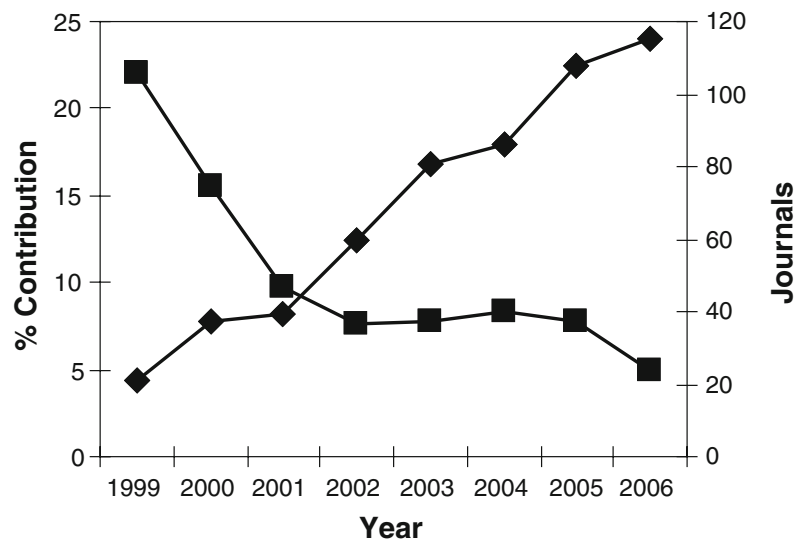

- \% journal Green Chemistry $\longrightarrow$ Journals

Fig. 2 The growth in number of journals that contained articles with the term green chemistry in their titles, abstracts and keywords and the percentage contribution in this respect of the journal Green Chemistry. Source: ISI Web of Knowledge: Web of Science 
disseminate awareness of environmentally compatible synthetic pathways (green chemistry)" (Bull 2000). In 2000, the first results of this working party were captured in a special issue of Pure and Applied Chemistry (vol. 72 (7), pp. 1207-1403), which also explains the lowering in percentage contribution of Green Chemistry as displayed in Fig. 2 for the year 2000. The green chemistry article of Anastas in this special issue was significantly cited, approximately 120 times (see footnote 9), evidence of the dissemination of this philosophy. In 2001, Pure and Applied Chemistry once again distributed two special issues on green chemistry (vol. 73 (1), pp. 77-203 and vol. 73 (8), pp. 1229-1330). Both issues were based on lectures presented at conferences that were held in 2001: the "International Symposium on Green Chemistry" in Delhi (India) and the "IUPAC CHEMRAWN XIV Conference on Green Chemistry: Toward Environmentally Benign Processes and Products" in Colorado (USA). The influence of these networking activities resulted in a huge green chemistry output for the years 2000 and 2001, which significantly explains the growth in green chemistry output, as displayed in Fig. 1.

The political support was to be continued in the early 2000s. This is reflected by the Presidential Green Chemistry Challenge Awards that were still annually granted, in accordance with the policy of the Pollution Prevention Act of 1990, and even more so by the statements of President George W. Bush who encouraged "leaders in science and industry to work together in the design, and implementation of green chemistry principles". ${ }^{10}$ Once more, this illustrates the eagerness of US politics to intensify the cooperation of the academic field and industry. Bush also referred to the green chemistry principles of the advocate of green chemistry, Anastas, who continued with the focus on this green chemistry philosophy. Hence, he commented in his most cited article that green chemistry is "intentionally designed" and "it is definitionally impossible to do green chemistry by accident" (Anastas and Kirchhoff 2002). Once again, it was mentioned somehow that green chemistry is a type of knowledge (see also "Introduction"). How seriously must this knowledge be taken? Till so far, Anastas' articles have been cited approximately 800 times (see footnote 9), which ought to be significant. Obviously, a significant number of chemists coalesced with this philosophy. A striking example in this case is Kidwai and Mohan (2005), they emphasized in this journal that green chemistry is "essentially a way of thinking". Phrases like "intentionally designed" and "essentially a way of thinking" imply that "knowledge" played an important role. Nevertheless, these phrases do not account for a sort of user friendliness within the green chemistry philosophy. For instance, Anastas and Kirchhoff (2002) labeled chemical research "that strives to incorporate one or more of the 12 principles" as "excellent". In addition, Anastas referred to these 12 principles as "guidelines" (see previous section). His statement that "it is definitionally impossible to do green chemistry by accident" contradicts claims about the work of the former Nobel Prize winners Knowles, Noyori and Sharpless. Their work were "predating the birth of green chemistry", but reflected "several of its ideals" (Poliakoff et al. 2002). This contrasts with the previous quotes "a way of thinking" and "intentionally designed". Obviously, it is possible to do green chemistry by accident, within the green chemistry concept advocated by Anastas. Warner and Anastas also outline comparable behavior in their handbook. In 1998, after the birth of green chemistry, they wrote their handbook. In the chapter References of this handbook they referred to the works of chemists (P. Tundo and J.W. Frost), which were developed before the birth of green chemistry (Anastas and Warner 1998, pp. 125-129).

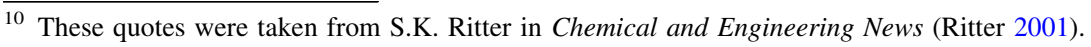


Thus, political support for US EPA was continued in the 2000s, so was the support of RSC for Green Chemistry. In 2004, Walter Leitner (2004) became the new scientific editor. He succeeded James Clark, which was bound to be a difficult task. During Clark's period, Green Chemistry developed in a very positive way. The reader audience of Green Chemistry grew, as did the reader audience of Clark's works (see footnote 9). Therefore, RSC was satisfied with the results obtained by Green Chemistry at that time. Considering the journal impact factor of 2, 54 in 2002, they had to be satisfied (Leitner 2004).

From 1999 up to and including 2003 Green Chemistry released six issues per year, but this changed with the appointment of Leitner. RSC was eager to support Green Chemistry, which resulted in an increase of publication rate to 12 issues per year from 2004 (Leitner 2004).

\section{Conclusions}

It is obvious that networking played a key role in the dissemination of green chemistry. Successful networking originated from contextual political, economic and environmental influences. It goes without a doubt that the observed political support for US EPA and the launching of Green Chemistry contributed significantly to the growth of green chemistry. This is especially true for the phase transition around 1998. Considering the close relation of green chemistry and political involvement (US politics), the growth of green chemistry is quite exceptional for the growth of a chemistry specialty. The political involvement in the growth of green chemistry was huge in comparison with traditional chemistry specialties, like for example physical chemistry (Levere 2001).

The spread of the term green chemistry and the green chemistry philosophy developed within US EPA did not always go hand in hand: the term was used by authors before Anastas published this philosophy in 1996, as can be seen in Cathcart (1990), Amato (1993) and Collins (1995).

Obviously, it is very tempting to use a term like "green chemistry" without giving any clear definition. The shift in terminology in 1996 (by Anastas) and the naming of the GCN journal in 1999 supports this claim. Before the growth around 1998, shortly after US EPA developed the green chemistry philosophy, authors used the term without referring to this philosophy (see footnote 9). See for example the significantly cited work of Bergbreiter (1998). This citing behavior continued from 1998 onwards; next to many other authors (see footnote 9), see for example the special issue in Chimia. In general, this citing behavior occurred at all stages of the growth (as described in the previous sections). Therefore, this reduces the importance of "knowledge" in the growth of green chemistry, as described in the Introduction. In fact, I suggest that apart from the increase in green chemistry "knowledge", there is "user friendliness" in the term green chemistry that significantly contributed to the growth of green chemistry. The citing behavior of authors at all stages of the growth confirms this claim. Apart from the user friendliness of the term, there is user friendliness within the proposed green chemistry philosophy. In this respect, the boundaries of this green chemistry are flexible. If chemical processes are qualified "excellent" by striving "to incorporate one or more of the 12 principles", then of course it is relatively easy to deserve the term green chemistry (Anastas and Kirchhoff 2002). In addition, analysis of the 12 principles elucidates that the principles obey a "should be sense" instead of a "must be sense" (see Table 1). According to Mullins' (1972) model which deals with scientific specialties, it is unlikely for these principles to be allowed as norms of a scientific specialty. Consequently, the greenness of many chemical processes that are within this 
green chemistry can be questioned (see footnote 9), as argued by Winterton (see the "Introduction").

In summary, capturing green chemistry in a single definition is difficult, because it is not a scientific specialty with a coherent conducted paradigm. Considering the role of "knowledge" (see "Introduction") on the growth of green chemistry, the scientific output (see Fig. 1) of green chemistry cannot be automatically epistemologically reduced to the green chemistry paradigm developed within US EPA (see citation statistics). Or following Crane (1969a), the users of the term green chemistry do not have "similar perceptions" of green chemistry (see for example the "Introduction"). So in fact, on the one hand the growth of green chemistry originates from political factors and networking activities. On the other hand, it is the result of user friendliness of the term and of the proposed philosophy itself.

Acknowledgments I kindly thank Prof. E. Homburg (Maastricht University, The Netherlands) and the anonymous reviewers for their critical comments on earlier versions of this manuscript. The Descartes Centre for the History and Philosophy of Sciences and the Humanities (Utrecht University, The Netherlands) and the Maastricht University (The Netherlands) are acknowledged for their financial support, as is T. Maaswinkel for his corrections of my English.

Open Access This article is distributed under the terms of the Creative Commons Attribution Noncommercial License which permits any noncommercial use, distribution, and reproduction in any medium, provided the original author(s) and source are credited.

\section{References}

Amato, I.: The slow birth of green chemistry. Science 259(5101), 1538-1541 (1993)

Anastas, P.T.: Benign by design chemistry. In: Anastas, P.T., Farris, C.A. (eds.) Benign by design; alternative synthetic design for pollution prevention, vol. 577, pp. 2-22. ACS Symposium Series, American Chemical Society, Washington, DC (1994)

Anastas, P.T., Farris, C.A.: Preface. In: Anastas, P.T., Farris, C.A. (eds.) Benign by design; alternative synthetic design for pollution prevention, vol. 577, pp. ix-x. ACS Symposium Series, American Chemical Society, Washington, DC (1994a)

Anastas, P.T., Farris, C.A.: Benign by design. In: Anastas, P.T., Farris, C.A. (eds.) Alternative synthetic design for pollution prevention, vol. 577. ACS Symposium Series, American Chemical Society, Washington, DC (1994b)

Anastas, P.T., Farris, C.A.: In memoriam. In: Anastas, P.T., Farris, C.A. (eds.) Benign by design; alternative synthetic design for pollution prevention, vol. 577, p. xi. ACS Symposium Series, American Chemical Society, Washington, DC (1994c)

Anastas, P.T., Kirchhoff, M.M.: Origins, current status, and future challenges of green chemistry. Acc. Chem. Res. 35(9), 686-694 (2002)

Anastas, P.T., Warner, J.C.: Green chemistry: theory and practice. Oxford University Press Inc., New York (1998)

Anastas, P.T., Williamson, T.C.: Green chemistry: an overview. In: Anastas, P.T., Williamson, T.C. (eds.) Green chemistry: designing chemistry for the environment, vol. 626, pp. 1-17. ACS Symposium Series, American Chemical Society, Washington, DC (1996a)

Anastas, P.T., Williamson, T.C. (eds.): Green chemistry: designing chemistry for the environment, vol. 626. ACS Symposium Series, American Chemical Society, Washington, DC (1996b)

Anastas, P.T., Williamson, T.C., Hjeresen, D., Breen, J.J.: Promoting green chemistry initiatives. Environ. Sci. Technol. 33(5), 116A-119A (1999)

Anastas, P.T., Kirchhoff, M.M., Williamson, T.C.: Catalysis as a foundational pillar of green chemistry. Appl. Catal., A. 221(11), 3-13 (2001)

Barnes, B., Edge, D. (eds.): Science in context; readings in the sociology of science. The Open University Press, Milton Keynes (1982)

Bergbreiter, D.E.: The use of soluble polymers to effect homogeneous catalyst separation and reuse. Catal. Today. 42(4), 389-397 (1998) 
Breen, J.J., Anastas, P.T.: Design for the environment: the environmental paradigm for the 21 st century. Chemtech. 24(7), 6-7 (1994)

Bull, J.R.: Preface. Pure Appl. Chem. 72(7), ii (2000)

Carson, R.: Silent spring. Houghton Mifflin Co., New York (1962)

Cathcart, C.: Green chemistry in the Emerald Isle. Chem. Ind. 5, 684-687 (1990)

Centi, G., Perathoner, S.: Catalysis and sustainable (green) chemistry. Catal. Today 77(4), 287-297 (2003)

Chuck, R.: A catalytic green process for the production of Niacin. Chimia. 54(9), 508-513 (2000)

Clark, J.H.: The greening of chemistry. Chem. Br. 34(10), 43-45 (1998)

Clark, J.H.: Editorial. Green Chem. 1(1), G1-G2 (1999a)

Clark, J.H.: Green chemistry: challenges and opportunities. Green Chem. 1(1), 1-8 (1999b)

Clark, J.H., Macquarrie, D.J.: Catalysis of liquid phase organic reactions using chemically modified mesoporous inorganic solids. Chem. Commun. 8, 853-860 (1998)

Collins, T.J.: Introducing green chemistry in teaching and research. J. Chem. Educ. 72(11), 965-966 (1995)

Crane, D.: Fashion in science: does it exist? Soc. Probl. 16(4), 433-441 (1969a)

Crane, D.: Social structure in a group of scientists: a test of the "invisible college" hypothesis. Am. Sociol. Rev. 34(3), 335-352 (1969b)

Eissen, M., Metzger, J.O.: Environmental performance metrics for daily use in synthetic chemistry. Chem Eur. J. 8(16), 3580-3585 (2002)

Hoffman, A.J.: From heresy to dogma; an institutional history of corporate environmentalism. The New Lexington Press, San Francisco (1997)

Kidwai, M., Mohan, R.: Green chemistry: an innovative technology. Foundations of Chemistry. 7, 269-287 (2005)

Klijn, J.E., Engberts, J.B.F.N.: Fast reactions 'on water'. Nature 435(7043), 746-747 (2005)

Latour, B.: Science in action. Harvard University Press, Massachusetts (1987)

Leitner, W.: Toward benign ends. Science. 284(5421), 1780-1781 (1999)

Leitner, W.: Green chemistry: a new phase. Green Chem 6(1), G1 (2004)

Levere, T.H.: Transforming matter; a history of chemistry from alchemy to the buckyball. The Johns Hopkins University Press, Baltimore (2001)

Long, B.L.: International environmental issues and the OECD 1950-2000. OECD, Paris (2000)

Macquarrie, D.J., Clark, J.H., Lambert, A., Mdoe, J.E.G., Priest, A.: Catalysis of the Knoevenagel reaction by $\gamma$-aminopropylsilica. React. Funct. Polym. 35, 153-158 (1997)

Morgenstern, D.A., LeLacheur, R.M., Morita, D.K., Borkowsky, S.L., Feng, S., Brown, G.H., Luan, L., Gross, M.F., Burk, M.J., Tumas, W.: Supercritical carbon dioxide as a substitute solvent for chemical synthesis and catalysis. In: Anastas, P.T., Williamson, T.C. (eds.) Green chemistry: designing chemistry for the environment, vol. 626, pp. 1-17. ACS Symposium Series, American Chemical Society, Washington, DC (1996)

Mullins, N.C.: The development of a scientific specialty: the phage group and the origins of molecular biology. Minerva. 10(1), 51-82 (1972)

Norton, M.B., Katzman, D.M., Escott, P.D., Chudacoff, H.P., Paterson, T.G., Tuttle, W.M., Brophy, W.J. (eds.): A people and a nation: a history of the United States. Houghton Mifflin Company, Boston (1991)

Poliakoff, M., Fitzpatrick, J.M., Farren, T.R., Anastas, P.T.: Green chemistry: science and politics of change. Science. 297(5582), 807-810 (2002)

Pollution Prevention Act of 1990. In: Compilation of selected acts within the jurisdiction of the committee on commerce: environmental law. US Government Printing Office, Washington (1995)

Rip, A.: Onderzoek van de Ontwikkeling van Wetenschapsgebieden. Kennis en Methode 1, 311-333 (1977)

Ritter, S.K.: Accepting the green challenge. Chem. Eng. News. 79(27), 24-28 (2001)

Roberts, J.A.: Creating green chemistry: discursive strategies of a scientific movement. Ph.D. Dissertation, Virginia Polytechnic Institute and State University, 13 Dec 2005. Also consultable via the Digital Library and Archives. http://scholar.lib.vt.edu/theses/available/etd-05042006-093037/ (2005). Accessed 19 July 2008

Simmons, M.S.: The role of catalysts in environmentally benign synthesis of chemicals. In: Anastas, P.T., Williamson, T.C. (eds.) Green chemistry: designing chemistry for the environment, vol. 626, pp. 1-17. ACS Symposium Series, American Chemical Society, Washington, DC (1996)

Stephan, D.G., Atcheson, J.: The EPA's approach to pollution prevention. Chem. Eng. Prog. 85(6), 53-58 (1989)

Stern, M.K.: Nucleophilic aromatic substitution for hydrogen; new halide-free routes for production of aromatic amines. In: Anastas, P.T., Farris, C.A. (eds.) Benign by design; alternative synthetic design for pollution prevention, vol. 577, p. xi. ACS Symposium Series, American Chemical Society, Washington, DC (1994) 
Tanko, J.M., Blackert, J.F., Sadeghipour, M.: Supercritical carbon dioxide as a medium for conducting freeradical reactions. In: Anastas, P.T., Farris, C.A. (eds.) Benign by design; alternative synthetic design for pollution prevention, vol. 577, p. xi. ACS Symposium Series, American Chemical Society, Washington, DC (1994)

Trost, B.M.: The atom economy—a search for synthetic efficiency. Science 254(5037), 1471-1477 (1991)

Tundo, P. (ed.): Collection of lectures of the summer schools on green chemistry, vol. 1. Green Chemistry Series, INCA, Italy (2001)

Tundo, P.: 1st meeting of the working party on green and sustainable chemistry. http://www.euchems.org/ binaries/1stWPGreenandSus28Feb08_tcm23-127739.pdf (2008). Accessed 22 July 2008

Winterton, W.: Science, scientists and sustainability. Clean Prod. Processes 3, 62-65 (2001) 